\title{
DEPOSITION OF AIRBORNE PARTICLES ONTO THE HUMAN EYE: WIND TUNNEL STUDIES OF THE DEPOSITION VELOCITY ONTO THE EYES OF A MANNEQUIN
}

\author{
A. Gudmundsson, ${ }^{* \dagger}$ T. Schneider ${ }^{\ddagger}$ M. Bohgard, ${ }^{*}$ P. Vinzents ${ }^{\ddagger}$ and K. R. Akselsson* \\ *Division of Working Environment, Lund Institute of Technology, P.O. Box 118, S-221 00 Lund, Sweden \\ ${ }^{\ddagger}$ National Institute of Occupational Health, Lersö Parkálle 105, D-2100 Copenhagen, Denmark
}

(First received 1 August 1995, in final form 14 November 1996)

\begin{abstract}
In the field of occupational hygiene much consideration is devoted to the uptake through the human airways, but there are also reports of irritations, complaints and hazards or potential hazards due to particle deposition onto the eyes. There is a need for data regarding the dependence of the deposition rate on particle size and environmental parameters in order to formulate sampling criteria and to find dose-response relations.

The deposition of airborne particles onto the human eye was studied by making use of a dummy, the eyes of which were covered with pieces of transparent sticky foil. The dummy was exposed to airborne particles in a wind tunnel. The airborne particle concentration was simultaneously measured using an Aerodynamic Particle Sizer ( $\Lambda$ PS, TSI Inc., U.S.A.). The deposited particles were counted using an optical microscope equipped with an image analyser. For the particle sizes $(2-30 \mu \mathrm{m})$, wind velocities $\left(0.5\right.$ and $\left.1.0 \mathrm{~m} \mathrm{~s}^{-1}\right)$, wind directions $\left(0,90\right.$ and $\left.180^{\circ}\right)$ and turbulence intensities ( 1.3 and $19 \%$ ) employed in this study, deposition velocities onto the eyes were determined to be in the range of $0.001-1 \mathrm{~cm} \mathrm{~s}^{-1}$. (C) 1997 Elsevier Science Ltd
\end{abstract}

\section{INTRODUCTION}

The outer surface of the eye is exposed to the surrounding air, and airborne particles can thus be deposited onto it. Several studies describe irritation, injuries, allergic reactions and diseases of the eye which may be caused by exposure to different aerosols in various environments. Schneider and Stokholm (1981) showed that man-made mineral fibres accumulated in the eyes of workers handling man-made mineral fibre products. A positive correlation was found between eye symptoms and the number of deposited fibres in the eye (Stokholm et al., 1982). Even in environments with lower concentration of fibres it was considered that fibres from ceiling tiles gave rise to eye complaints (Verbeck et al., 1981; Alsbirk et al., 1983; Rindel et al., 1987). Tobacco dust has been reported to cause eye irritation among workers in tobacco industries (Lander, 1986; Kjaergaard and Pedersen, 1989). Deposition of bioparticles (e.g. airborne particles of spores, pollen, viruses, mite fragments) onto the eyes may cause allergic response or infections (Evans, 1989; Ryan, 1990; Lacey and Dutkiewicz, 1994). The occurrence of allergic symptoms of itching eyes due to exposure to wood dust is described by Herold et al. (1991). Symptoms defined as sick building syndrome (SBS) are suggested to arise from dust containing microorganisms (Gravesen et al., 1986). In attempts to quantify the risk of conjunctival contamination in connection with operation by surgeons, the number of visible blood splashes on spectacles and on protective glasses has been investigated (Brearley and Buist, 1989; Stokes et al., 1990; Schnetler, 1991; Prior et al., 1993) and the number concentration of airborne bloodassociated particles has been determined (Yeh et al., 1995). The implications of airborne particles to eye and skin irritations in connection with work with CRT displays (Olsen, 1981; Hedge et al., 1992) and in sick-buildings (Quackenboss and Lebowitz, 1989; Skov et al., 1990; Hodgson et al., 1991; Hedge et al., 1992; McDonald et al., 1993; Franck et al., 1993) are also debated. In an investigation at Swedish schools (Norbäck et al., 1990),

${ }^{\dagger}$ Author to whom correspondence should be addressed. 
a connection between eye irritation and the concentration of respirable fraction particles was obtained.

In summary, studies which are aimed at finding relations between concentrations of airborne particles in various environments and the degree of eye manifestations in exposed individuals are inconclusive. Measurements of airborne particles are performed employing methods (Vincent, 1989), whose common features are they are designed to reflect the health effects of airborne particles which can reach different sites in the respiratory system. In some studies, the airborne particles are collected with total aerosol samplers. In other investigations, samplers designed for collecting the respirable fraction are used. There is, however, a lack of knowledge regarding how aerosols should be sampled to reflect the probability of deposition on the eye. Improved knowledge on how different environmental parameters affect the deposition probability of particles of different sizes is essential in order to develop measurement and monitoring techniques which reflect the degree of deposition. Better measurement techniques are a prerequisite for designing studies aimed at increasing our knowledge of the relationships between exposure to airborne particles and hazards, irritations and discomforts of the eyes.

The deposition rate is usually expressed as the deposition velocity $v_{\text {dep }}\left(\mathrm{m} \mathrm{s}^{-1}\right)$, which is the effective velocity with which the particles migrate to the surface, and is defined as

$$
v_{\text {dep }}=\frac{J}{C_{0}}=\frac{N}{A t C_{0}},
$$

where $J\left(\mathrm{~m}^{-2} \mathrm{~s}^{-1}\right)$ is the particle deposition flux, $C_{0}\left(\mathrm{~m}^{-3}\right)$ the undisturbed particle concentration in air, $N$ the number of particles deposited, $A\left(\mathrm{~m}^{2}\right)$ the area of the exposed surface and $t(\mathrm{~s})$ the exposure time. In this work, the deposition velocity is defined for an open eye (i.e. the blockage due to blinking is disregarded) and determined as a surface-averaged deposition rate over the open eye. If the deposition velocity is known, the number of particles deposited per unit time can be estimated by measuring the airborne particle concentration. The deposition velocity is influenced by various transport mechanisms, e.g. diffusion, thermophoresis, convection, impaction, turbulent diffusion and migration in electrical fields.

The objective of this study was to gain knowledge about the deposition velocity as a function of the aerodynamic particle diameter and the dependence of deposition velocity on parameters such as mean velocity, turbulence intensity and direction of the surrounding air flow. This knowledge is necessary when developing criteria and methods for sampling of airborne particles, which can be related to the probability of deposition onto the human eyes.

The deposition velocity of airborne particles was studied using a dummy exposed to airborne particles in a wind tunnel. Before exposure, both eyes of the dummy were covered with a clean, sticky and transparent foil. During exposure the particle concentration and size distribution of the airborne particles were measured. After exposure, the pieces of foil were removed and placed on microscope slides. Using an optical microscope equipped with an image analyser, the number and size of the particles deposited on the foil were determined.

A semiempirical model, based on limited data from this work (only the $1 \mathrm{~m} \mathrm{~s}^{-1}$ results was used), predicting the deposition velocity on eyes and facial skin dependence on impaction, turbulent diffusion and migration in electrical fields was presented by Schneider et al. (1994). Preliminary experimental results from this study were presented. There are minor discrepancies (mainly all differences within one standard deviation) in the results presented in this paper and the preliminary ones which appeared in the work by Schneider et al. (1994).

\section{EXPERIMENTAL SET-UP}

\section{Wind tunnel system and aerosol generation}

The wind tunnel was of a low-speed, open-cycle type. The working section of the wind tunnel, where the dummy was placed, is schematically shown in Fig. 1. The tunnel was 

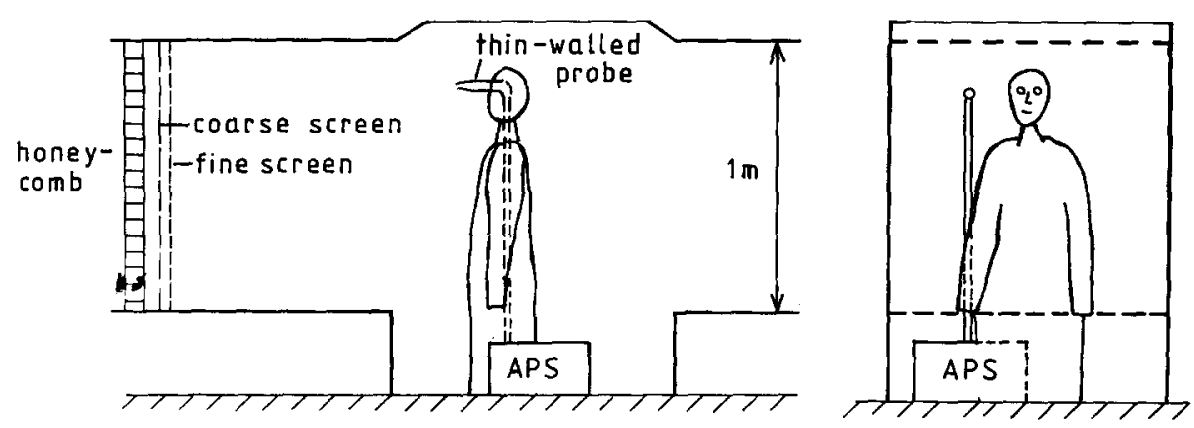

Fig. 1. The working section of the wind tunnel showing the location of the dummy. The airborne particles were sampled with a thin-walled probe with a sampling flow rate of $1.01 \mathrm{~min}^{-1}$ and transported through a tube directly connected to the inner nozzle of an Aerodynamic Particle Sizer (APS, model 33B, TSI Inc.).

supplied with filtered, heated air. During all the experiments, the tunnel air temperature was $20 \pm 1{ }^{\circ} \mathrm{C}( \pm \sigma)$. The main working section was $1.0 \mathrm{~m}$ wide and $1.1 \mathrm{~m}$ high. The airborne particles were sampled isokinetically with a thin-walled probe. The sampling flow rate was $16.7 \mathrm{~cm}^{3} \mathrm{~s}^{-1}$ and the aerosol was transported directly to the inner nozzle of an Aerodynamic Particle Sizcr (APS, model 33B, TSI Inc., U.S.A.), which was placed below the dummy. The diameter of the thin-walled probe was changed to maintain isokinetic conditions when the air velocity in the wind tunnel was varied.

The air velocity was measured with a constant-temperature anemometer system (IFA 100 , TSI Inc., U.S.A.), with a maximum sampling rate of $200 \mathrm{kHz}$. The probe used, a single, cylindrical hot-film sensor (diameter $50 \mu \mathrm{m}$ and length $10 \mathrm{~mm}$, model $1220-20$, TSI Inc., U.S.A.) could be moved using a traverse system.

To obtain a homogeneous flow field and a low turbulence intensity in the working section, an alumina grid with a honeycomb structure and two different screens of stainless steel were placed upstream from the working section. The honeycomb, with a thickness of $70 \mathrm{~mm}$ and hexagonal channels with sides of $4 \mathrm{~mm}$, was placed $1.1 \mathrm{~m}$ in front of the dummy. The dimensions of the screens are described using the wire diameter, $d_{\mathrm{w}}$, and the mesh width, $M_{\mathrm{w}}(=$ distance between the centre of two wires). The solidity, $S$, of the screen is defined as the ratio of the projected solid area to total area. The coarsest screen $\left(d_{\mathrm{w}}=1.0 \mathrm{~mm}, M_{\mathrm{w}}=3.2 \mathrm{~mm}\right.$ and $\left.S=0.53\right)$ was placed $0.05 \mathrm{~m}$ downstream from the honeycomb and a finer screen $\left(d_{\mathrm{w}}=0.24 \mathrm{~mm}, M_{\mathrm{w}}=0.59 \mathrm{~mm}\right.$ and $\left.S=0.65\right)$ a further $0.05 \mathrm{~m}$ downstream.

An increased turbulence intensity in the working section was generated with a biplane grid made of wooden rods of square cross-section $\left(20 \times 20 \mathrm{~mm}^{2}, M_{\mathrm{w}}=80 \mathrm{~mm}\right.$ and $\left.S=0.44\right)$ placed in front of the working section $(0.8 \mathrm{~m}$ downstream from the finer screen). When the dummy was placed for exposure at high air flow turbulence intensity, it was positioned $0.17 \mathrm{~m}$ downstream the grid.

Alumina particles (Aloxite dust, grade F500, Washington Mills Electro Minerals Limited, Manchester, UK) were emitted into the air using a dispersion generator (RBG-1000, Palas $\mathrm{GmbH}, \mathrm{Karlsruhe}$, Germany). The particles were fed into a high-turbulent part of the wind tunnel, $1.0 \mathrm{~m}$ upstream from the honeycomb, so that a high degree of mixing was obtained. The particle size distribution of the dispersed powder, sampled isokinetically in the working section and measured with the APS, is shown in Fig. 2. The size distribution is corrected due to particle losses in the sampling line, coincidence error in the APS and incorrectness in particle size determination of the APS. The correction procedure is described in the next section.

\section{The dummy and the eyes}

The dummy was a full-size torso, wearing a laboratory coat of cotton. It blocked $\sim 30 \%$ of the cross-section of the wind tunnel when it was facing the wind and $\sim 16 \%$ when the side was directed toward the wind. 


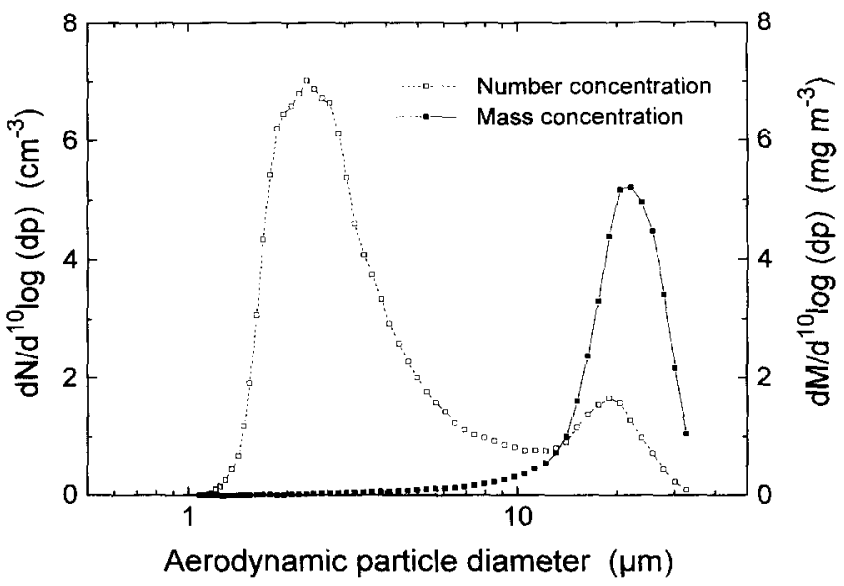

Fig. 2. Particle size distribution of the alumina particles, sampled isokinetically in the working section and determined using the APS.
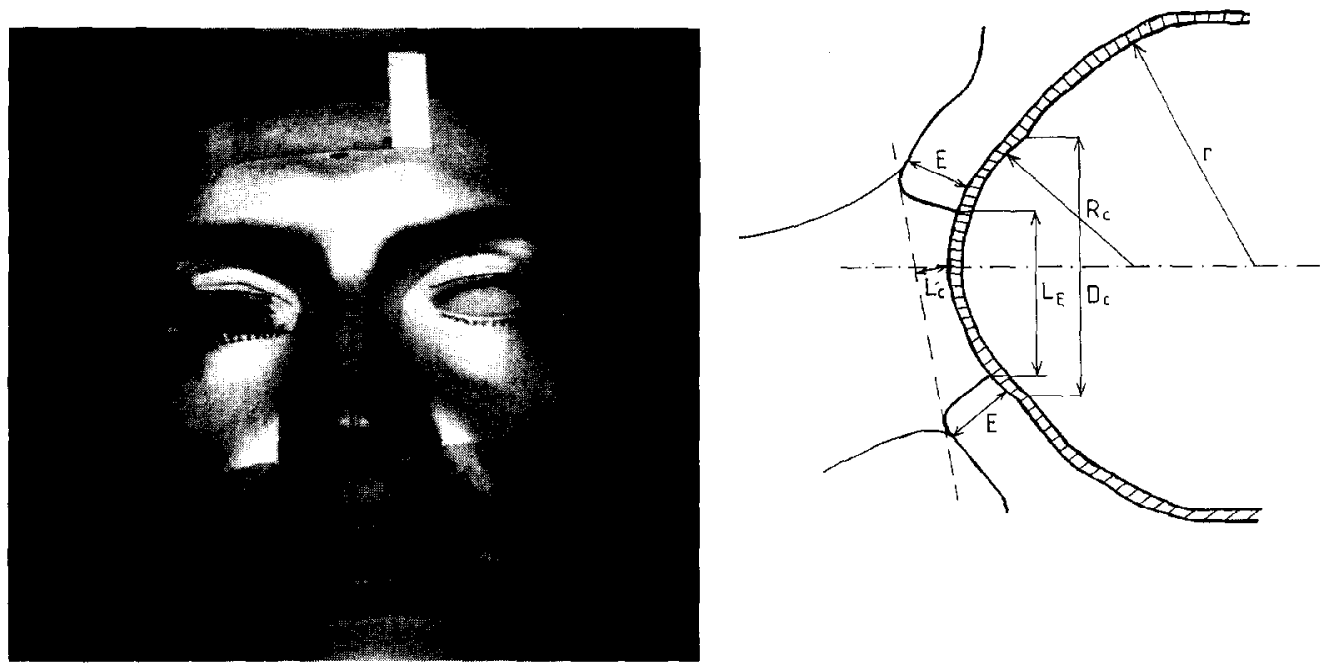

Fig. 3. (Left) The head showing the left eye mounted and covered with foil, the right eye removed and the forehead foil mounted. The bright part of the head is a conductive layer. (Right) Dimensions of the eye with foil mounted. $R_{\mathrm{C}}=$ radius of corneal curvature $(8 \mathrm{~mm}), D_{\mathrm{c}}=$ diameter of the cornea $(12 \mathrm{~mm}), r=$ radius of the eyeball $(12 \mathrm{~mm}), E=$ thickness of the eyelids $(3-4 \mathrm{~mm}), L_{\mathrm{E}}=$ maximum distance between the eyelids (left eye $9 \mathrm{~mm}$ and right eye $7 \mathrm{~mm}$ ), $L_{\mathrm{c}}=$ distance between the top of the cornea and a line between the outer edge of the eyelids $(2-3 \mathrm{~mm})$. The eyelashes, for cosmetic use, were made of human head hair, with a diameter of $0.07 \mathrm{~mm}$. Upper eyelashes consisted of about 120 hair with lengths in the range $6-8 \mathrm{~mm}$, and the lower eyelashes consisted of about 100 hair with lengths in the range $5-7 \mathrm{~mm}$.

The eyes of the dummy (Fig. 3, left) were made of acrylic material and were castings of an eye prosthesis. The eyes were removable from the eye socket. The dimensions of the eye casting and the lids of the dummy were within $\pm 20 \%$, and the eyelashes within $\pm 30 \%$ compared with data given by von Lanz and Wachsmuth (1979) and Hollwich (1985) (Fig. 3, right). The arca of the cye cxposed to the surrounding air, $A_{\text {eye }}$ was for the left cyc, $1.8 \pm 0.05 \mathrm{~cm}^{2}( \pm \sigma)$ and the right, $1.2 \pm 0.05 \mathrm{~cm}^{2}$. The eyes were covered with a sticky gelatine foil (fingerprint lifters) with a thickness of $0.5 \mathrm{~mm}$ on which particles were collected. The foil covered the eye smoothly and could easily be removed and mounted flat on a microscope slide for analysis. The eye sockets and the lids were carefully designed so that the foil covering the eyes fitted tightly against the edge of inner side of the lids. Eyebrows or 
hair on the head of the dummy were not used in order to avoid contamination of the foil. A foil measuring $25 \times 50 \mathrm{~mm}^{2}$ was also mounted on the forehead, using double-sided tape. The face of the head was covered with a conductive layer of silver paint.

\section{Optical microscopy}

Images of the foil were recorded using an optical microscope (Vanox-T, Olympos) with a video camera (MTI, Dage). Using an image analyser (IBAS, Kontron), the equivalent projected area diameter, $d_{\mathrm{pa}}$, was determined for particles greater than $\sim 2 \mu \mathrm{m}$. An objective of the magnification $20 \times$ was used. For the digitised image, one pixel was equivalent to a square of $0.46 \times 0.46 \mu \mathrm{m}^{2}$. The images, each corresponding to an area, $A_{\mathrm{i}}$, of $0.0436 \mathrm{~mm}^{2}$ on the foil, were homogeneously distributed over the exposed area of the foil. The number of images, $n$, studied was between 60 and 120 . The total analysed area, $A_{\mathrm{a}}$, of each foil was equal to $n A_{\mathrm{i}}$. The ratio of analysed and exposed area of the eye foil, $K_{\mathrm{A}}=A_{\mathrm{a}} / A_{\text {eye }}$, was $\sim 4 \%$. The eye foil was stretched when it was applied to the eye and contracted when it was removed. The shrinkage of the foil was determined as the ratio $K_{\mathrm{f}}=A_{\text {mic }} / A_{\text {eye }}$, where $A_{\text {mic }}$ is the area of the exposed surface of the foil when placed on the microscope slide. The particles were classified into 6 particle size intervals and for each interval the number of particles, $N_{\text {mic }}$, on the analysed area, $A_{\mathrm{a}}$, was determined. The total number of particles, $N_{\text {eye }}$, for each particle size interval on the foil was then calculated using

$$
N_{\text {eye }}=\frac{N_{\text {mic }} K_{\mathrm{f}}}{K_{\mathrm{A}}}
$$

\section{PROCEDURE}

\section{Particle concentration characteristics}

The thin-walled probe was placed on the right side and at the same height as the eyes of the dummy, with the orifice of the probe $10 \mathrm{~cm}$ in front of the face of the dummy. The distance between the right side of the head and the thin-walled probe was $13 \mathrm{~cm}$. No disturbance could be observed due to the thin-walled probe on the flow pattern in front of the dummy at any orientation of the dummy using visual inspection with smoke. Particle sampling, with and without the dummy in the working section, showed that the influence of the dummy on the particle concentration at the probe site was less than $5 \%$ for all particle size intervals. When no alumina particles were generated, the total particle concentration was less than $1 \mathrm{~cm}^{-3}$ measured with the APS. The above-mentioned investigations were performed at an air flow velocity of $1.0 \mathrm{~m} \mathrm{~s}^{-1}$ and a turbulence intensity of $1.3 \%$.

The particle concentration was measured, using the APS, across the central part of the working section in the absence of the dummy (Fig. 4). The orifice of the thin-walled probe was placed in the plane containing the eyes of the dummy when it was in position of exposure, facing the wind. The particle concentration was measured every $5 \mathrm{~cm}$ along a horizontal line at the same height as the eyes and at $10 \mathrm{~cm}$ intervals along a vertical line between the eyes. This was performed four times at a mean velocity of $1.0 \mathrm{~m} \mathrm{~s}^{-1}$ and turbulence intensity of $1.3 \%$. For each of the six particle size intervals the distribution of the relative particle concentration was determined. Figure 4 shows the relative particle concentrations of particles in the interval, $25-32 \mu \mathrm{m}$, which were most unevenly distributed. The relative particle concentration for the other particle size intervals was closer to 1 . The relative particle concentration was also measured under two other conditions, namely when the mean velocity was $1.0 \mathrm{~m} \mathrm{~s}^{-1}$ and the turbulence intensity $19 \%$ and when the mean velocity was $0.50 \mathrm{~m} \mathrm{~s}^{-1}$ and the turbulence intensity $1.3 \%$. No significant difference $\left(\leqslant \pm 10 \%\right.$ ) from that determined at $1.0 \mathrm{~m} \mathrm{~s}^{-1}$ and the turbulence intensity $1.3 \%$ was observed, except for the particle concentration in the vertical direction at $0.50 \mathrm{~m} \mathrm{~s}^{-1}$ (Fig. 4). 


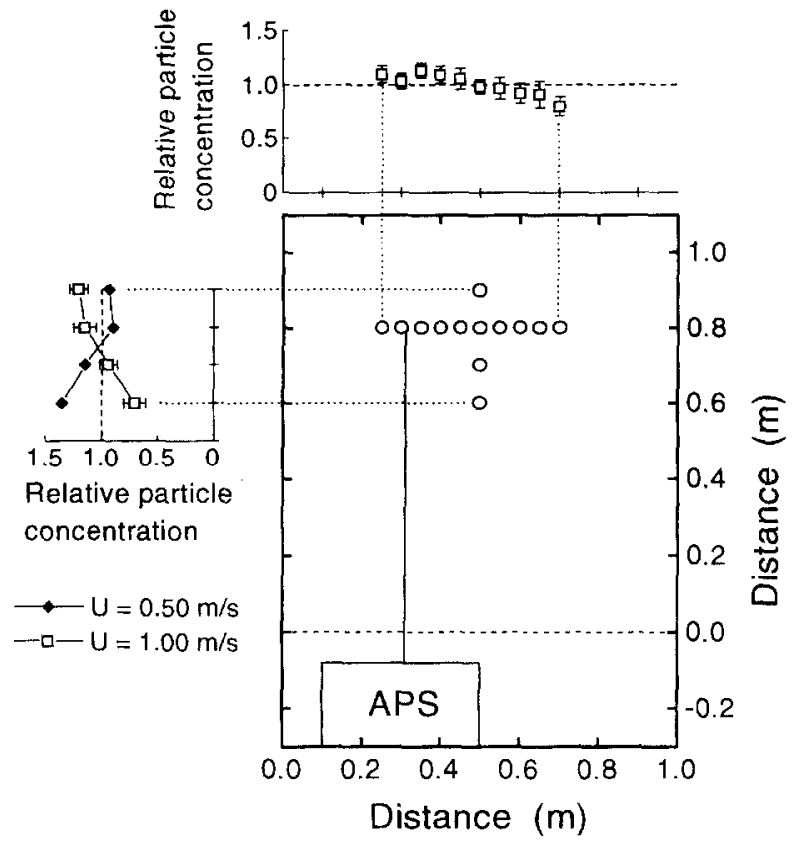

Fig. 4. For the plane perpendicular to the air flow, containing the eyes of the dummy, the particle concentration was measured four times across the central part of the working section, in the absence of the dummy. The mean air velocity was $1.0 \mathrm{~m} \mathrm{~s}^{-1}$ and the turbulence intensity was $1.3 \%$. The diagrams show the relative particle concentration of the particles in the interval $25-32 \mu \mathrm{m}$ based on measurements along the horizontal line (10 measurement points) and the vertical line (4 measurement points). The error bars show the standard deviation of the distribution of measured particle concentrations ( 4 measurements). The relative particle concentration in the vertical direction is also shown for an air velocity of $0.50 \mathrm{~m} \mathrm{~s}^{-1}$ and turbulence intensity of $1.3 \%$.

\section{Flow characteristics}

The single hot-film sensor was calibrated by the manufacturer at low turbulence intensity. Measurements of the velocity fluctuation velocity in the main air flow direction, $u$, performed in air flows with high turbulence intensity were corrected for velocity fluctuation components $(v$ and $w$ ) perpendicular to the main stream direction (Hinze, 1975). The turbulence intensity, $T$, in the main air flow direction, defined as the ratio of the velocity fluctuation velocity and the mean air velocity, $U$, was determined by the following procedure. With the sensor perpendicular to the main stream direction the effective mean air velocity, $U_{\text {eff }}$, and the velocity fluctuation velocity, $u_{\mathrm{eff}}$, was measured. The true value of the mean air velocity, $U$, and velocity fluctuation, $u$, in the main air flow direction was then obtained using

$$
\begin{gathered}
U=\frac{U_{\mathrm{eff}}}{1+h^{2} \frac{1}{2} \frac{v^{2}}{U^{2}}+k^{2} \frac{1}{2} \frac{w^{2}}{U^{2}}}, \\
u^{2}=\frac{u_{\mathrm{eff}}^{2}}{1+h^{2} \frac{1}{2} \frac{v}{u} \frac{v}{U}+k^{2} \frac{1}{2} \frac{w}{u} \frac{w}{U}},
\end{gathered}
$$

where the values of the constants $h$ and $k$ depend on the dimensions and physical properties of the sensor. Results from Groth and Johansson (1988), who performed measurements of the turbulence downstream of grids and screens with similar dimensions to those used here, were used to estimate the degree of anisotropy, i.e. the ratios $v / u$ and $w / u$. Empirically 
determined values of $h$ and $k$ were taken from Fingerson and Freymuth (1983). All measurements were performed with a sampling interval of $2 \mathrm{~ms}$ and 16,000 samples were taken during $32 \mathrm{~s}$.

A grid was placed in front of the working section. The solidity, $S$, of the grid was 0.44 and the turbulence downstream the grid can be assumed to be stable (Baines and Peterson, 1951). Figure 5 shows how that turbulence intensity decreased with increasing distance behind the gird. Figure 6 (left) shows the velocity distribution measured $0.17 \mathrm{~m}$ behind the grid at a mean velocity of $1.0 \mathrm{~m} \mathrm{~s}^{-1}$ and a turbulence intensity of $19 \%$. The mannequin was placed at this distance downstream the grid to obtain an air flow with "high" turbulence. The turbulence anisotropy behind a biplane grid with similar dimensions $\left(6 \times 6 \mathrm{~mm}^{2}, M_{\mathrm{w}}=25 \mathrm{~mm}\right.$ and $\left.S=0.42\right)$ has been studied by Groth and Johansson (1988). They showed that the turbulence became isotropic at 10-20 mesh widths. From their data the anisotropy $0.17 \mathrm{~m}$ behind the grid (about 2.1 mesh widths) can be estimated to be about 1.1. Without the grid, the turbulence intensity was $1.3 \%$ (later mentioned as "low" turbulence) at a mean velocity of $1.0 \mathrm{~m} \mathrm{~s}^{-1}$ (Fig. 6, right). The distance to the screens was $1.1 \mathrm{~m}$ and the turbulence can be assumed to be both stable and isotropic.

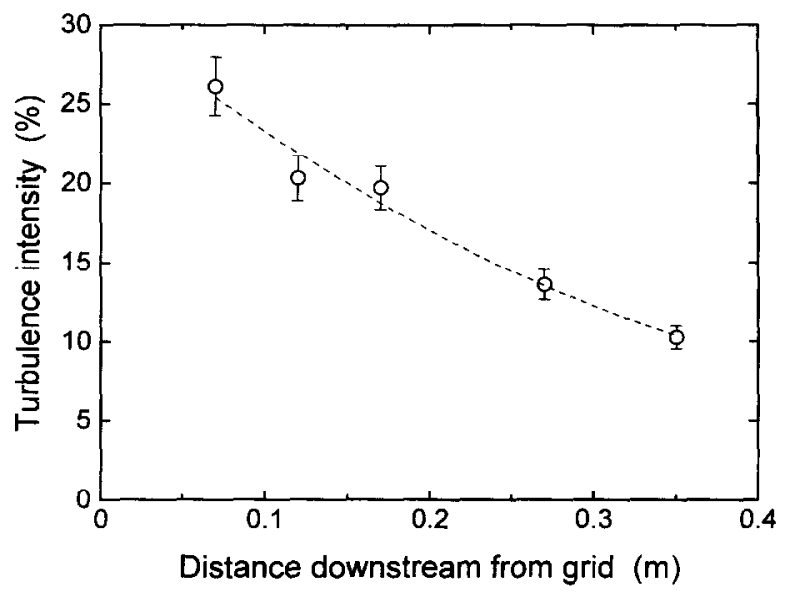

Fig. 5. The turbulence intensity as a function of the distance downstream from the grid measured in the absence of the dummy in the wind tunnel. The error bars show the precision of the sampling (the standard deviation) calculated due to the sample time used (32 s) and the time integral scale estimated $(65 \mathrm{~ms})$.
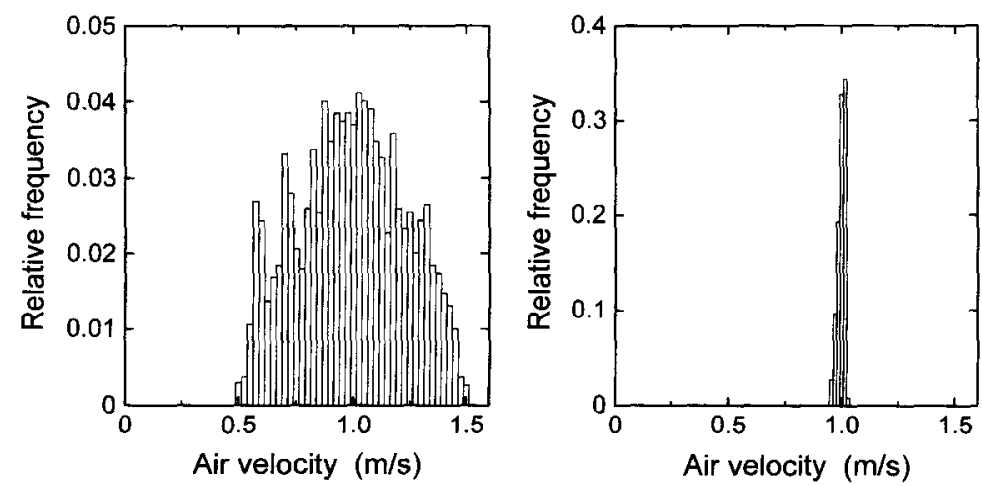

Fig. 6. The velocity distribution at a mean velocity of $1.0 \mathrm{~m} \mathrm{~s}{ }^{1}$. (Left) High turbulence intensity $19.0 \%$. (Right) Low turbulence intensity $1.3 \%$. The measurements were performed without the dummy in the working section, at a location which coincided with a point situated half way between the eyes of the dummy when it was in position for exposure and facing the wind. 
The stability of the air flow in the working section was investigated by measuring the mean air velocity and the turbulence intensity 60 consecutive times with the same parameters during $1 \mathrm{~h}$ (the maximum time of exposure of the dummy). The relative standard deviation of the mean velocities at 0.50 and $1.00 \mathrm{~m} \mathrm{~s}^{-1}$ was less than $4.0 \%$. The relative standard deviation of the turbulence intensity at low and high turbulence intensity was less than $8.0 \%$. These measurements were performed at the position which corresponded to a point situated half way between the eyes of the dummy when it was in position for exposure.

The air velocity distribution at 1.0 and $0.50 \mathrm{~m} \mathrm{~s}^{-1}$ was measured at 39 sites across the central part of the working section, in the plane perpendicular to the wind and containing the eyes of the dummy, when it was in position for exposure. The measuring points were distributed along three horizontal lines: one $10 \mathrm{~cm}$ above the eyes of the dummy, one at the same height and one $10 \mathrm{~cm}$ below. The 13 measuring points along each level extended $25 \mathrm{~cm}$ to the left and $25 \mathrm{~cm}$ to the right from the middle of the head. At low turbulence intensity $(1.3 \%)$ the relative standard deviation of the mean velocity was less than $6.0 \%$ and of the turbulence intensity less than $9.0 \%$. At high turbulence intensity $(19 \%)$, the corresponding relative standard deviations were less than $15 \%$.

Calculation of the time correlation was performed to estimate the integral time scale. The air velocity was sampled with a sampling interval of $1.0 \mathrm{~ms}$. At a wind velocity of $1.0 \mathrm{~m} \mathrm{~s}^{-1}$ and at low turbulence intensity $(1.3 \%)$ the integral time scale was $20 \mathrm{~ms}$ and at high turbulence intensity (19\%) the integral time scale was $65 \mathrm{~ms}$. The characteristic macrolength scale was estimated using Taylor's hypothesis (Hinze, 1975). The estimated length scale was $20 \mathrm{~mm}$ at a turbulence intensity of $1.3 \%$ and $65 \mathrm{~mm}$ at a turbulence intensity of $19 \%$.

The integral time scale has been used to estimate an appropriate sample time (Hinze, 1975). Using a sample time of $32 \mathrm{~s}$ and a sampling frequency of $500 \mathrm{~Hz}$, the mean velocities and turbulence intensities were measured with a precision better than $1 \%$, except for the measurements of the turbulence intensities downstream the grid. For instance, $0.17 \mathrm{~m}$ downstream the grid, the turbulence intensity of $19 \%$ was determined with a precision better than $7 \%$.

\section{Particle size calibration}

The deposition velocity was determined as a function of the aerodynamic particle diameter and it was assumed that the deposition of airborne particles onto the eye occurs under or close to Stokesian condition (the particle Reynolds number was estimated to be $<2$ ). The response of the APS is based on the behaviour of rigid and smooth spheres with unit density. Due to the high air velocity $\left(150 \mathrm{~ms}^{-1}\right)$ in the measuring volume, the aerodynamic particle diameter determined by the $\Lambda$ PS $\left(d_{\text {APS }}\right)$ is dependent on the shape and density of the particles (Griffiths et al., 1984; Cheng et al., 1990). To obtain the particle size of the irregular alumina particles used in this study in terms of true aerodynamic particle diameter, calibration of the particle size determination of the APS and the microscope was performed (Gudmundsson et al., 1991).

Five impactors operating in the range $1.0<\operatorname{Re}_{\mathrm{p}}<3.0$ (cut-off diameters $2-20 \mu \mathrm{m}$, air velocities 1-20 $\mathrm{m} \mathrm{s}^{-1}$, inlet pressure $1013 \mathrm{mbar}$ and pressure drops 0.4-4 mbar) were used for the calibration. The cut-off diameters were calculated (Marple and Willeke, 1976) and taken as the true aerodynamic particle diameters, $d_{\mathrm{a}}$. The penetration curves of the impactors were determined by comparison of the output particle concentrations when the alumina particles were sampled with and without impaction plate in the impactor housing. The output particle concentration was measured with the APS or collected on filters for later microscopy studies. To obtain unity penetration for particles less than $\sim 30 \%$ of the cut-off diameter, correction factors in the range $0.94-1.06$ were used with an average correction of $4 \%$. For each impactor the cut-off diameter was determined five times using the APS (Fig. 7, left) and the microscope (Fig. 7, right). The APS-data was corrected for particle density using a universal procedure described by Wang and John (1989). The 

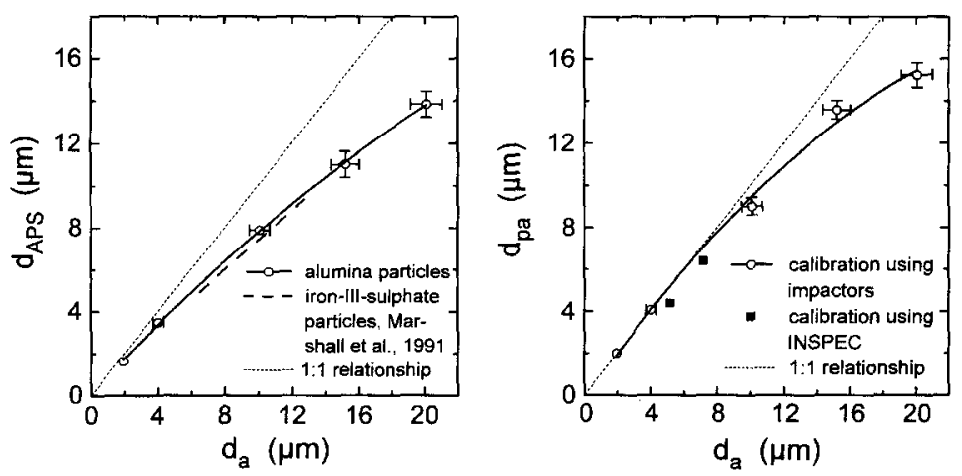

Fig. 7. (Left) The relationship between the aerodynamic particle diameter $d_{\text {APS }}$ determined using the APS corrected for particle density (Wang and John, 1989) and the true aerodynamic particle diameter $d_{\mathrm{a}}$ of the alumina particles. (Right) The relationship between the projected particle diameter $d_{\mathrm{pa}}$ determined using a microscope and the true aerodynamic particle diameter $d_{\mathrm{a}}$ of the alumina particles. INSPEC is a inertial spectrometer developed by Prodi et al. (1979). The error bars show the standard deviation of the distribution ( 5 measurements). The relative standard deviation of $d_{\mathrm{a}}$ was estimated to be less than $5 \%$

density of the individual alumina particles was assumed to be the same as the bulk density $3.96 \times 10^{3} \mathrm{~kg} \mathrm{~m}^{-3}$ (value provided by the manufacturer, Washington Mills Electro Minerals Limited, Manchester, U.K.).

For the same specific grade of alumina powder as that used here (Aloxite, grade F500, supplied by the same manufacturer), Mark et al. (1985) determined the dynamic shape factor to be 1.24 expressed as a mean value for the entire particle distribution. The determined APS response of the alumina particles agrees with a study of the APS response of regular-shaped non-spherical iron-III sulphate particles (Marshall et al., 1991) (Fig. 7, left). These particles have approximately the same particle density, $3.1 \times 10^{3} \mathrm{~kg} \mathrm{~m}^{-3}$, and dynamic shape factor, $1.19 \pm 0.06$.

The alumina particles were also sampled using an inertial spectrometer (INSPEC) (Prodi et al., 1979). The projected area diameter of the deposited particles in the inertial spectrometer was measured using the microscope and compared with the aerodynamic particle diameter given by the calibration curve of the inertial spectrometer provided by the manufacturer (Fig. 7, right).

\section{Number calibration}

Losses in the thin-walled probe and the sampling tube to the APS together with internal losses in the APS and coincidence effects in the APS (Heitbrink et al., 1991) caused a discrepancy between the particle concentration detected with the APS ( $\left.C_{\mathrm{APS}}\right)$ and the true particle concentration $C_{0}$ of the undisturbed concentration. To determine the ratio $K_{s}=C_{0} / C_{\text {APS }}$ (equation (4) and Table 1), alumina particles were sampled simultaneously with a membrane filter (type HAWP 02500, Millipore Corp., MA, U.S.A.) and with the APS. This was done three times. Sampling with the filter was performed with a mouthpiece identical to the one used for the APS measurements. The simultaneous sampling was performed under isokinetic conditions at an air velocity of $1.0 \mathrm{~m} \mathrm{~s}^{-1}$ and the total particle concentration was the same as that during the exposure of the dummy, 150-200 particles $\mathrm{cm}^{-3}$, to obtain the same level of coincidence effects in the APS.

To determine the true undisturbed concentration $C_{0}$, the penetration loss in the filter mouthpiece was determined. The interior of the filter mouthpiece was rinsed with a solution of distilled water and a dispersion agent $\left(0.5 \%\right.$ sodium hexamethaphosphate $\left.\left(\mathrm{NaPO}_{3}\right)_{x}\right)$ and the solution was filtered through a membrane filter (type HAWP 02500, Millipore Corp., MA, U.S.A.). The number of particles lost in the filter mouthpiece, $N_{\mathrm{f}}$, was assumed to be the number of particles on the membrane filter determined using the microscope. The number 
Table 1. Correction factor $K_{\mathrm{s}}$ ( \pm standard error of mean), the ratio of the true particle concentration $C_{0}$ of the undisturbed concentration and the particle concentration detected with the APS, $C_{\text {APS }}$

\begin{tabular}{ccc}
$\begin{array}{c}\text { Aerodynamic particle size } \\
\text { interval of the APS } \\
(\mu \mathrm{m})\end{array}$ & $\begin{array}{c}\text { True aerodynamic } \\
\text { particle size interval } \\
(\mu \mathrm{m})\end{array}$ & $K_{\mathrm{s}}$ \\
\hline $2.1-3.6$ & 1.93 .5 & $0.76 \pm 0.04$ \\
$3.7-5.8$ & $3.6-6.7$ & $0.84 \pm 0.07$ \\
$5.9-9.2$ & $6.7-10.1$ & $1.19 \pm 0.20$ \\
$9.3-14.5$ & $10.2-16.2$ & $1.94 \pm 0.20$ \\
$14.6-22.6$ & $16.3-25.6$ & $2.68 \pm 0.28$ \\
$22.7-28.2$ & $25.7-32.1$ & $4.41 \pm 0.91$ \\
\hline
\end{tabular}

* Particle size without correction for particle density.

${ }^{+}$According to impactor cut-off diameters.

of particles simultaneously collected on the filter of the mouthpiece, $N_{\mathrm{m}}$, and sampled using the APS, $N_{\mathrm{APS}}$, was determined. $K_{\mathrm{s}}$ (Table 1 ) was then determined using

$$
K_{\mathrm{S}}=\frac{C_{0}}{C_{\mathrm{APS}}}=\frac{N_{\mathrm{f}}+N_{\mathrm{m}}}{N_{\mathrm{APS}}}
$$

\section{Exposure procedure}

Before exposure, the head and the eyes were washed with distilled, deionized and filtered water, rinsed with ethanol, dried and placed in a clean air flow bench. The foils were mounted on the eyes. The eyes were mounted in the eye sockets and a piece of foil was placed on the forehead. The head was then mounted on the torso. During exposure, the airborne particle concentration and size distribution were measured with the APS.

After exposure, the head was removed and placed in the clean air flow bench. The foil was stretched when it was applied to the eyes and contracted when it was removed. To be able to correct for the change in area, the edge of the exposed area of the eye foil was engraved using a needle before removing the eye from the eye socket. The foil was placed on a microscope slide and the area of the exposed surface $A_{\text {mic }}$, was determined using image analysis. To determine the level of possible contamination, blanks were used. On three occasions, blanks were employed in a similar fashion to that described above except that the dummy was placed for only a short time (about $10 \mathrm{~s}$ ) in the wind tunnel when no alumina particles were generated and the fans of the wind tunnel were turned off.

\section{DATA PROCESSING AND CORRECTION}

The number of particles, $N_{\text {mic }}^{\mathrm{B}}$, detected on each blank was between 2 and 7 (Table 2). The average total number of particles on the blanks $\bar{N}_{\text {eye }}^{\mathrm{B}}$ for each particle interval was calculated using

$$
\bar{N}_{\mathrm{cye}}^{\mathrm{B}}=\overline{\left(\frac{N_{\mathrm{mic}}^{\mathrm{B}} K_{\mathrm{f}}}{K_{\mathrm{A}}}\right)} .
$$

The number of images analysed on the blanks and the eye foils were about the same. The lowest possible detectable deposition velocity $\left(v_{\text {det }}\right.$, detection limit) depends on the undisturbed particle concentration, exposure time, the number of images analysed and the number of particles on the blanks (contamination). To calculate $v_{\text {det }}$ two assumptions were made. First, the detection limit regarding deposition velocity corresponds to the number of particles on the eye foil, $\left(N_{\text {det }}\right)$, that significantly exceeded the number of particles on the blanks, which was taken to be equal to $\bar{N}_{\text {eye }}^{\mathrm{B}}+2 \sigma_{\text {eye. }}^{\mathrm{B}}$. Second, not more than one particle was present in each image and the number of images containing a particle was a binomial 
Table 2. Number of particles detected on the blanks, $N_{\text {mic }}^{\mathrm{B}}$. Originally, 3 blanks were used for each eye but one (right eye) was neglected due of obvious incorrect handling

\begin{tabular}{llllllll}
\hline $\begin{array}{l}\text { Midpoint aerodynamic } \\
\text { particle diameter } \\
(\mu \mathrm{m})\end{array}$ & $\begin{array}{l}\text { Left } \\
\text { eye }\end{array}$ & $\begin{array}{l}\text { Right } \\
\text { eye }\end{array}$ & $\begin{array}{l}N_{\text {mic }}^{\mathbf{B}} \\
\text { Left } \\
\text { eye }\end{array}$ & $\begin{array}{l}\text { Right } \\
\text { eye }\end{array}$ & $\begin{array}{l}\text { Left } \\
\text { eye }\end{array}$ & $\begin{array}{l}\bar{N}_{\text {mic }}^{\mathbf{B}} \\
\text { Mean } \\
\text { value }\end{array}$ & $\begin{array}{l}\sigma_{\text {mic }}^{\mathbf{B}} \begin{array}{l}\text { Standard } \\
\text { deviation }\end{array} \\
2.7\end{array}$ \\
\hline 4.7 & 2 & 1 & 3 & 2 & 3 & 2.20 & 0.84 \\
7.9 & 2 & 0 & 1 & 3 & 3 & 1.80 & 1.30 \\
12.9 & 0 & 0 & 1 & 0 & 0 & 0.20 & 0.45 \\
20.5 & 0 & 0 & 0 & 1 & 0 & 0.20 & 0.45 \\
28.7 & 0 & 1 & 0 & 0 & 0 & 0.20 & 0.45 \\
\hline
\end{tabular}

distribution. From that, $v_{\text {det }}$ was then determined so that if the deposition velocity was equal to the detection limit, the probability of counting more than $N_{\text {det }}$ particles was at least $90 \%$.

The deposition velocities were determined using equation (1). The number of particles on the eye foil $N_{\text {eye }}$ (equation (2)) was subtracted by the mean number of particles on the blanks $\bar{N}_{\text {eye }}^{\mathrm{B}}$. The true undisturbed particle concentration $C_{0}$ is given by the concentration $C_{\mathrm{APS}}$ (particle concentration measured with the APS) corrected by multiplying with the correction factor $K_{\mathrm{S}}$ (equation (4)). Thus,

$$
v_{\text {dep }}=\frac{N_{\text {eye }}-\bar{N}_{\text {eye }}^{\mathrm{B}}}{A_{\text {eye }} t C_{0}}=\frac{\frac{N_{\text {mic }} K_{\mathrm{f}}}{K_{\mathrm{A}}}-\overline{\left(\frac{N_{\mathrm{mic}}^{\mathrm{B}} K_{\mathrm{f}}}{K_{\mathrm{A}}}\right)}}{A_{\text {eye }} t C_{\mathrm{APS}} K_{\mathrm{S}}},
$$

where variables with superscript $B$ are for blanks.

\section{RESULTS}

\section{Comparison of the deposition velocity of the left and right eye at $0^{\circ}$}

A comparison of the deposition velocity on the left and right eye was performed for the experiments when the dummy was facing the wind. For each particle size interval, 11 ratios were determined. The mean value for each particle size was close to $1.0(0.94 \pm 0.09)( \pm \sigma)$, $\min 0.82$, max 1.05). This means that the deposition velocity was virtually the same for the left and right eye, despite the fact that the left eye had 1.50 greater exposed area (1.8 and $1.2 \mathrm{~cm}^{2}$, respectively). From now on we will refer to the deposition velocity at 0 and $180^{\circ}$ as the mean value of the corresponding deposition velocity obtained from left and right eyes.

\section{Deposition velocities onto the eye}

The range of the parameters is shown in Table 3. The dummy was exposed in the wind tunnel on 18 occasions, which resulted in 36 exposed pieces of eye foil. The deposition velocity dependence on the aerodynamic particle diameter at different values of the air velocity, the turbulence intensity and the orientation of the dummy is shown in Figs $8 \mathrm{a}-\mathrm{d}$.

When the dummy was facing the wind at a mean velocity of $1.0 \mathrm{~m} \mathrm{~s}^{-1}$ and a turbulence intensity of $1.3 \%$, the deposition velocity increased weakly with increasing aerodynamic particle diameter (Fig. 8a). The deposition velocity was between 0.02 and $0.09 \mathrm{~cm} \mathrm{~s}^{-1}$ in the particle size range $2-30 \mu \mathrm{m}$. The deposition was determined six times (12 pieces of eye foil). For each particle size interval the standard deviation of the distribution (S.D.) of the deposition velocities was determined. The values of the S.D. were about the same, $60 \pm 15 \%$ of the mean. This uncertainty was assumed to be valid for all other determined 
Table 3. Experimental range of parameters

\begin{tabular}{llll}
\hline $\begin{array}{l}\text { Air } \\
\text { velocity } \\
\left(\mathrm{m} \mathrm{s}^{-1}\right)\end{array}$ & $\begin{array}{l}\text { Turbulence } \\
\text { intensity } \\
(\%)\end{array}$ & $\begin{array}{l}\text { Orientation } \\
\text { to the wind } \\
(\mathrm{deg})\end{array}$ & $\begin{array}{l}\text { Number } \\
\text { of pieces } \\
\text { of eye foil }\end{array}$ \\
\hline 1.0 & 1.3 & 0 & 12 \\
1.0 & 1.3 & 90 & 2 \\
1.0 & 1.3 & 180 & 4 \\
0.5 & 1.3 & 0 & 4 \\
0.5 & 1.3 & 90 & 4 \\
0.5 & 1.3 & 180 & 4 \\
1.0 & 19.0 & 0 & 6 \\
\hline
\end{tabular}

* Angle between dummy and wind direction: $0^{\circ}=$ the dummy facing the wind, $90^{\circ}=$ left side directed towards the wind, $180^{\circ}=$ the back directed towards the wind.

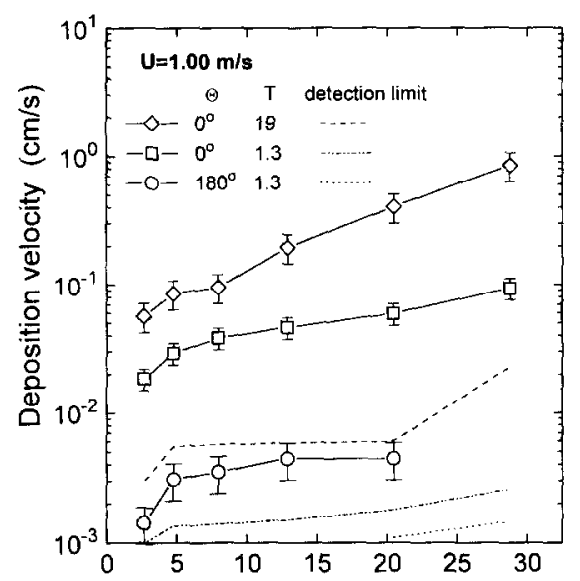

(a) Aerodynamic particle diameter $(\mu \mathrm{m})$

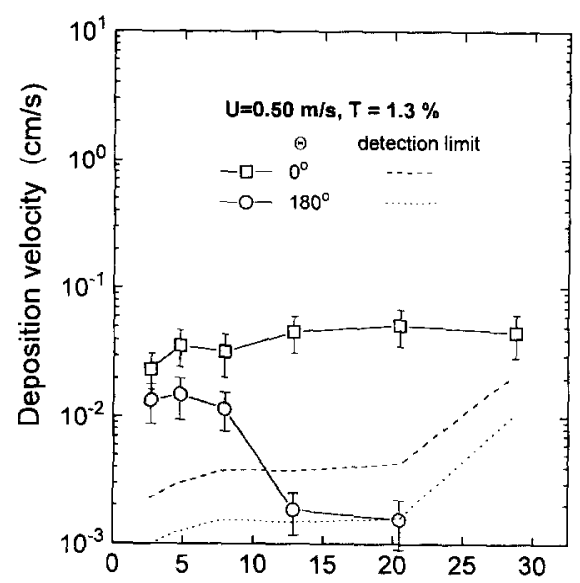

(c)

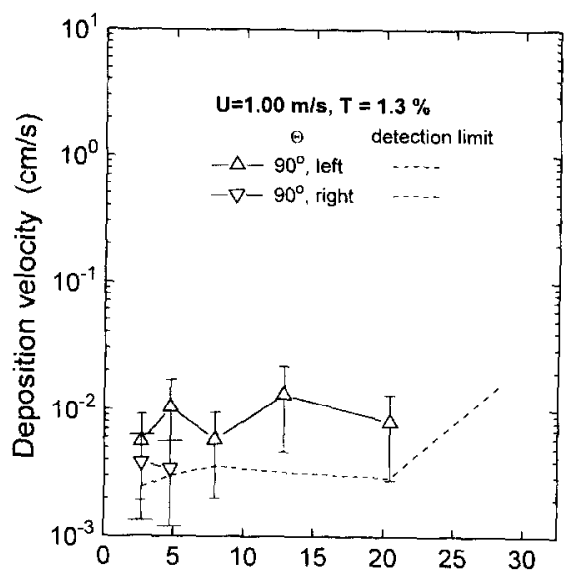

(b) Aerodynamic particle diameter $(\mu \mathrm{m})$

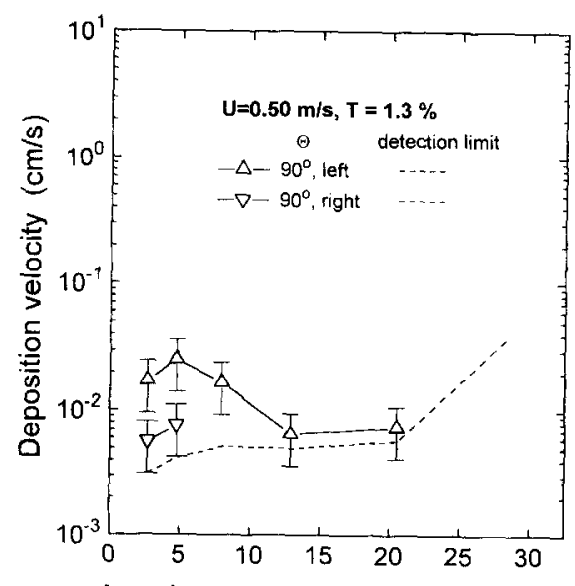

(d)

Fig. 8(a-d). The deposition velocity under different environmental conditions regarding orientation to the wind $(\theta)$, air velocity $(U)$ and turbulence intensity $(T)$ of the air flow. The error bars show the standard error of mean. Dotted lines show the detection limit of the deposition velocity. 


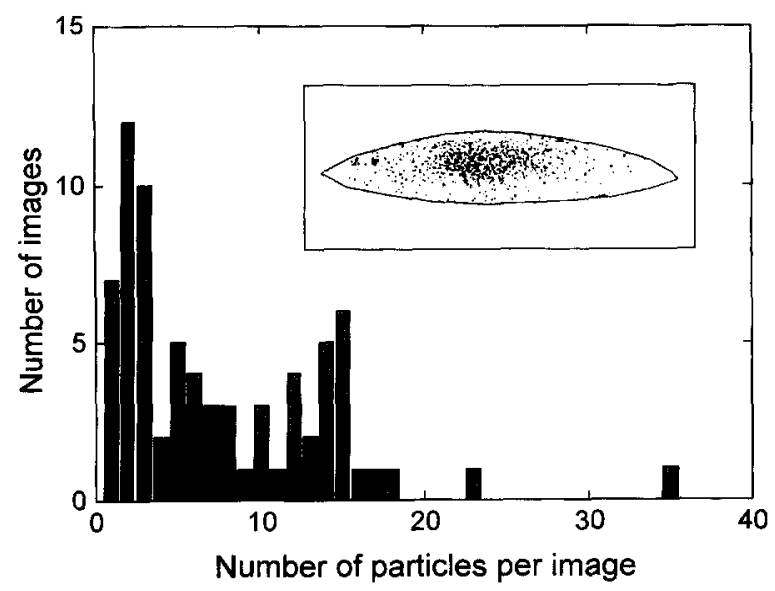

Fig. 9. An example of the distribution of the number of particles counted per image. The figure also shows the area density of particles on the eye foil.

deposition velocities. The standard error of mean (S.E.) for the determined deposition velocities is defined as S.D. $/ \sqrt{n}$, where $n$ is the number of measurements.

When the dummy was turned 90 and $180^{\circ}$ relative to the wind direction (Figs $8 \mathrm{a}-\mathrm{d}$ ) the deposition velocity decreased compared to when it was facing the wind (Figs $8 \mathrm{a}$ and c). For the right eye, when the dummy was oriented $90^{\circ}$ to the air flow, the deposition velocity decreased rapidly, and for particles greater than about $8 \mu \mathrm{m}$ the deposition velocity was lower than the detection limit. No deposition velocities were determined for the largest particle size interval due to the high detection limit. Changing the wind velocity from 1.0 to $0.50 \mathrm{~m} \mathrm{~s}^{-1}$, when the dummy was facing the air flow, caused only a small change in the deposition velocity (Figs $8 \mathrm{a}$ and $\mathrm{c}$ ).

An increase in the turbulence intensity from 1.3 to $19 \%$ increased the deposition velocity by a factor of more than 3 for all particle sizes (Fig. 8a) and the deposition velocity increased more strongly with increasing particle size.

The deposition velocity at the forehead was also determined in a number of experiments when the dummy was facing the air flow with a mean velocity of $1.0 \mathrm{~m} \mathrm{~s}^{-1}$ and a turbulence intensity of $1.3 \%$. Comparisons show that the deposition velocity onto the eye varied between 20 and $35 \%$ of the deposition velocity onto the forehead.

The particles were unevenly distributed over the surface of the eye. Figure 9 shows a typical distribution of the particles on the foil when the dummy was facing the air flow at a mean air velocity of $1.0 \mathrm{~m} \mathrm{~s}^{-1}$ and a turbulence intensity of $1.3 \%$.

\section{DISCUSSION}

The experiments were performed with a dummy with eyes that that could not blink. The deposition rate onto the eyes of a real human being will be reduced by blinking. The reduction depends on the duration of the blinking and the frequency of blinking. The normal blink rate is often given as $12-15$ per minute and the total blink duration is approximately $0.26 \mathrm{~s}$ (Doane, 1994). The time period for which the eye is partially or totally protected by the lids is therefore less than $4 \mathrm{~s}$ per minute and the maximum reduction of the deposition rate will roughly be about $7 \%$.

The blinking rate can be influenced by factors as air flow, gases, dust, stress, etc. In field studies in coal mines, Gibson and Vincent (1980) have compared particle deposition onto the eyes for miners and a dummy exposed to bursts of coarse dust. They suggested that the blinking reflex reduces the maximum particle size that impacts onto the human eyes to 
about $120 \mu \mathrm{m}$. The blinking reflexes should therefore not affect the deposition velocity of particles of sizes determined in this study $(2-30 \mu \mathrm{m})$ if these particles do not occur simultaneously with much coarser particles.

The deposition velocity onto the eyes is less than that on the forehead. It appears that the eyes are partly protected against particle deposition due to the shape of the face.

If the surface temperature of the human body is greater than the temperature of the surrounding air, upward convective air movements are formed. The significance of such air movements on the flow pattern around the body decreases with increasing surrounding air velocities. In realistic indoor environments, with lower velocities than those used in this study the convective currents may be significant.

The aerosol was neutralized and the charging of the dummy was not completely eliminated (maximum potential $< \pm 300 \mathrm{~V}$ ). To gain more complete knowledge about the deposition rate of airborne particles onto the human eye, the influence of particle migration in electrical fields must be considered. Theoretical considerations show that the importance of the presence of electrical fields increases with decreasing particles size (Schneider et al., 1994). If the deposition velocities of heavily charged particles or particles smaller than that used in this study are considered, the influence of particle migration due to electrical fields must be addressed. At low air velocities a heated dummy should be used so that thermal convection is included in the flow pattern around the dummy. Furthermore, the experiments with different turbulent intensities show that in wind tunnel studies of deposition in the eye, the flow must have a turbulence intensity similar to that which exists in realistic environments as low turbulence intensities (which often occur in wind tunnels), can give too low estimations of realistic deposition rates.

\section{CONCLUSIONS}

For the particle sizes, wind velocities, wind directions and turbulence intensities employed in this study, deposition velocities in the eyes were determined to be in the range $0.001-1 \mathrm{~cm} \mathrm{~s}^{-1}$

For the dummy facing the wind the following conclusions could be drawn.

- At a mean velocity of $1.0 \mathrm{~m} \mathrm{~s}^{-1}$ and a turbulence intensity of $1.3 \%$ the deposition velocity increased weakly with increasing aerodynamic particle diameter and is in the range $0.01-0.1 \mathrm{~cm} \mathrm{~s}^{-1}$.

- Changing the wind velocity from 1.0 to $0.50 \mathrm{~m} \mathrm{~s}^{-1}$ caused only small changes in the deposition velocity.

- The turbulence intensity has a major influence on the deposition velocity for all particle sizes. An increase in the turbulence intensity from 1.3 to $19 \%$ increased the deposition velocity to the range $0.1-1 \mathrm{~cm} \mathrm{~s}^{-1}$.

When the side or the back of the dummy was directed towards the wind, the deposition velocity was much lower than when the dummy was facing the wind. Depending on the particle size, orientation and wind velocity, the deposition velocity was in the range $0.001-0.01 \mathrm{~cm} \mathrm{~s}^{-1}$.

For the dummy facing the wind at a mean velocity of $1.0 \mathrm{~m} \mathrm{~s}^{-1}$ and a turbulence intensity of $1.3 \%$ the deposition velocity onto the eye was, depending on particle size, between 20 and $35 \%$ of the deposition velocity onto the forehead.

Acknowledgements-The authors would like to thank Ms Dorte Narv and Ms Signe H. Nilsen for their patient work at the microscope. Thanks are also due to Mr Jan Sjögren, who constructed the experimental set-up and arranged the eye prosthesis and eye castings. This project was financed by the Swedish Council for Work (Nos. 90-672 and 94-0338).

\section{REFERENCES}

Alsbirk, K., Johansson, M. and Petersen, R. (1983) Øjensymptoner og eksponering for mineralfibre fra lyddaempande loftsplader. Ugeskr. Laeger 145, 43-47 (in Danish).

Baines, W. D. and Peterson, E. G. (1951) An investigation of flow through screens. Trans. ASME 73, $467-480$. 
Brearly, S. and Buist, L. J. (1989) Blood splashes: an und erestimated hazard to surgcon. BMJ 299, 1315.

Cheng, Y. S., Chen, B. T. and Yeh, H. C. (1990) Behaviour of isometric nonspherical aerosol particles in the Aerodynamic Particle Sizer. J. Aerosol Sci. 21, 701-710.

Doane, M. G. (1994) Tear film and blink dynamics. In Principles and Practice of Ophthalmology. Basic Sciences (Edited by Albert, D. M. and Jakobiec, F. A.), pp. 1049-1055. W. B. Saunders Company, Philedelphia.

Evans, A. S. (1989) Viral infections of Humans. Plenum, New York.

Fingerson, L. M. and Freymuth, P. (1983) Thermal anemometers. In Fluid Mechanics Measurements (Edited by Goldstein, R. J.). Hemisphere, New York.

Franck, C., Bach, E. and Skov, P. (1993) Prevalence of objective eye manifestations in people working in office buildings with different prevalences of the sick building syndrome compared with the general population. Int. Arch. Occup. Envir. Hith 65, 65-69.

Gibson, H. and Vincent, J. H. (1980) On the inpaction of airbone coarse dust into the eyes of human subjects. Ann. Occup. Hyg. 23, 35-45.

Gravesen, S., Larsen, L., Gyntelberg, F. and Skov, P. (1986) Demonstration of microorganisms and dust in schools and offices. Allergy 41, 520-525.

Griffiths, W. D., Patrick, S. and Rood, A. P. (1984) An aerodynamic particle size analyser tested with spheres, compact particles and fibres having a common settling rate under gravity. J. Aerosol Sci. 15, 491-502.

Groth, J. and Johansson, A. (1988) Turbulence reduction by screens. J. Fluid Mech. 197, 139-155.

Gudmundsson, A., Petersen, O. H., Schneider, T. and Bohgard, M. (1991) Particle size calibration between the aerodynamic particle sizer and optical microscope for wind tunnel studies with particles of fused alumina. J. Aerosol Sci. 22, 347-351.

Hedge, A., Erickson, W. A. and Rubin, G. (1992) Why do gender, job stress, perceived indoor air quality and VDT use influence reports of the sick building syndrome in office. Proc. Work with Display Units, Berlin, 1992, Institut für Arbeitswissenschaft, Technische Universität Berlin.

Heitbrink, W. A., Baron, P. A. and Willeke, K. (1991) Coincidence in time-of-flight aerosol spectrometers: phantom particle creation. Aerosol Sci. Technol. 14, 112-126.

Herold, D. A., Wahl, R., Maasch, H. J., Hausen, B. M. and Kunkel, G. (1991) Occupational wood-dust sensitivity from Euonymus europaeus (spindle tree) and investigation of cross reactivity between E.e. wood and Artemisia vulgaris pollen (mugwort). Allergy 46, 186-190.

Hinze, J. O. (1975) Turbulence, 2nd Edition. McGraw-Ilill, New York.

Hodgson, M. J., Frohliger, J., Permar, E., Tidwell, C., Traven, N. D., Olenshuk, S. A. and Karpf, M. (1991) Symptoms and microenvironmental measures in nonproblem buildings. J. Occup. Med. 33, 527-533.

Hollwich, F. (1985) Ophthalmology: a Short Textbook. Georg Thieme Verlag, Stuttgart.

Kjaergaard, S. K. and Pedersen, O. F. (1989) Dust exposure, eye redness, eye cytology and mucous membrane irritation in tobacco industry. Int. Arch. Occup. Envir. Hlth 61, 519-525.

Lacey, J. and Dutkiewicz, J. (1994) Bioaerosols and occupational lung disease. J. Aerosol Sci. 25, 1371-1404.

Lander, F. (1986) Forekomsten af akutte og kroniske lungesygdomme i tobaksindustrien. Ugeskr. Laeger 148, $1697-1700$.

Von Lanz, T. and Wachsmuth, W. (1979) Praktische Anatomie, Vol. 1:3. Springer, Berlin.

McDonald, J. C., Armstrong, B., Bénard, J., Cherry, N. M. and Farant, J. P. (1993) Sick building syndrome in a Canadian office complex. Arch. Envir. Hlth 48, 298-304.

Mark, D., Vincent, J. H., Gibson, H. and Witherspoon, W. A. (1985) Applications of closely graded powders of fused alumina as test dust for aerosol studies. $J$. Aerosol $S$ ci. 16, 125-131.

Marple, V. A. and Willeke, K. (1976) Impactor design. Atmos. Envir. 10, 891

Marshall, I. A., Mitchell, J. P. and Griffiths, W. D. (1991) The behaviour of regular-shaped non-spherical particles in a TSI aerodynamic particle sizer. J. Aerosol Sci. 22, 73-89.

Norbäck, D., Torgén, M. and Edling, C. (1990) Volatile organic compounds, respirable dust, and personal factors related to prevalence and incidence of sick building syndrome in primary schools. Br. J. Ind. Med. 47, $733-741$.

Olsen, W. C. (1981) Electric field enhanced aerosol exposure in visual display unit environments. CMI No 803604-1, Chr. Michelsen Institute, Bergen

Prior, A. J., Montgomery, P. Q. and Srinivasan, V. (1993) Eye protection in ear, nose and throat surgery. J. Laryngol. Otol. 107, 618-619.

Prodi, V. C., Melandri, G., Tarroni, T., De Zaiacomo, M., Formignani, M. and Hochrainer, D. (1979) An inertial spectrometer for aerosol particles. .J. Aerosol Sci. 10, 411

Quackenboss, J. J. and Lebowitz, M. D. (1989) Indoor-outdoor relationships for particulate matter: exposure classifications and health effects. Envir. Int. 15, 353-360.

Rindel, A., Bach, E., Breum, N. O., Hugod, C. and Schneider, T. (1987) Correlating health effect with indoor air quality in kindergartens. Int. Arch. Occup. Envir. Hith 59, 363-373.

Ryan, K. J. (1990) Medical Microbiology, 3rd Edition. Prentice-Hall, Englewood Cliffs, NJ.

Schneider, T., Bohgard, M. and Gudmundsson, A. (1994) A semiempirical model for particle deposition onto facial skin and eyes. Role of air currents and electric fields. J. Aerosol Sci. 25, 583-593.

Schneider, T. and Stokholm, J. (1981) Accumulation of fibers in the eyes of workers handling man-made mineral fiber products. Scand. J. Work Envir. Hlth 7, 271-276.

Schnetler, J. F. C. (1991) Blood splashes to the eye in oral and maxillofacial surgery, and the risks of HIV transmission. Br. J. Oral. Maxillofac. Surg. 29, 338-340.

Skov, P., Valbjörn, O., Pedersen, B. O. and the Danish Indoor Climate Study Group (1990) Influence of indoor climate on the sick building syndrome in an office environment. Scand. J. Work Envir. Hith 16, $363-371$.

Stokes, A. N., Burton, J. F. and Beale, R. R. (1990) Eye protection in dental practice. New Zealand Dental J. 86, $14-15$.

Stokholm, J., Norn, M. and Schneider, T. (1982) Ophthalmologic effects of man-made mineral fibers. Scand. $J$. Work Envir. Hith 8, 185-190. 
Verbeck, S. J. A., Buise-van Unnik, E. M. M. and Malten, K. E. (1981) Itching in office workers from glass fibres. Concat Derm. 7, 354.

Vincent, J. H. (1989) Aerosol Sampling: Science and Practice. Wiley, New York.

Wang, H.-C. and John, W. (1989) A simple iteration procedure to correct for the particle density effect in the aerodynamic particle sizer. Aerosol Sci. Technol. 10, 501-505.

Yeh, H. C., Muggenburg, B. A., Guilmette, R. A., Snipes, M. B., Turner, R. S., Jones, R. K. and Smith, J. P. (1995) Characterization of aerosols produced during total hip replacement surgery in dogs with ${ }^{51} \mathrm{Cr}$-labeled blood. J. Aerosol Sci. 26, 511-518. 